\title{
Retrograde traffic in the biosynthetic-secretory route
}

\author{
Margit Pavelka $\cdot$ Josef Neumüller $\cdot$ Adolf Ellinger
}

Accepted: 9 January 2008 / Published online: 13 February 2008

(C) Springer-Verlag 2008

\begin{abstract}
In the biosynthetic-secretory route from the rough endoplasmic reticulum, across the pre-Golgi intermediate compartments, the Golgi apparatus stacks, trans Golgi network, and post-Golgi organelles, anterograde transport is accompanied and counterbalanced by retrograde traffic of both membranes and contents. In the physiologic dynamics of cells, retrograde flow is necessary for retrieval of molecules that escaped from their compartments of function, for keeping the compartments' balances, and maintenance of the functional integrities of organelles and compartments along the secretory route, for repeated use of molecules, and molecule repair. Internalized molecules may be transported in retrograde direction along certain sections of the secretory route, and compartments and machineries of the secretory pathway may be misused by toxins. An important example is the toxin of Shigella dysenteriae, which has been shown to travel from the cell surface across endosomes, and the Golgi apparatus en route to the endoplasmic reticulum, and the cytosol, where it exerts its deleterious effects. Most importantly in medical research, knowledge about the retrograde cellular pathways is increasingly being utilized for the development of strategies for targeted delivery of drugs to the interior of cells. Multiple details about the molecular transport machineries involved in retrograde traffic are known; a high number of the molecular constituents have been characterized, and the complicated fine structural architectures of the compartments involved become more and more visible. However, multiple contradictions exist, and already established traffic models
\end{abstract}

M. Pavelka ( () ) J. Neumüller · A. Ellinger

Department of Cell Biology and Ultrastructure Research, Center for Anatomy and Cell Biology,

Medical University of Vienna, Schwarzspanierstrasse 17,

1090 Vienna, Austria

e-mail: margit.pavelka@meduniwien.ac.at again are in question by contradictory results obtained with diverse cell systems, and/or different techniques. Additional problems arise by the fact that the conditions used in the experimental protocols frequently do not reflect the physiologic situations of the cells. Regular and pathologic situations often are intermingled, and experimental treatments by themselves change cell organizations. This review addresses physiologic and pathologic situations, tries to correlate results obtained by different cell biologic techniques, and asks questions, which may be the basis and starting point for further investigations.

Keywords Biosynthetic secretory route .

Retrograde traffic $\cdot$ ER $\cdot$ Golgi apparatus $\cdot$ Endocytosis

\section{Introduction}

The biosynthetic-secretory route is traveled by newly synthesized luminal and membrane proteins and glycoproteins from their sites of synthesis at bound ribosomes of the rough endoplasmic reticulum (RER) to their final destinations inside and outside the cells (for review e.g. Farquhar and Hauri 1997; Mellman and Warren 2000). It involves complex and highly dynamic organelles, such as the Golgi apparatus, pre-Golgi intermediates, and post-Golgi organelles, which all have central roles in transport regulation, sorting, and targeting. The route that leads out of the RER at special ER-export sites, involves complicated ER-Golgi intermediate compartments, enters the Golgi apparatus stacks at their cis side, leads across the stacks of Golgi cisternae, where the traversing molecules are subjected to major modifications, and continues at the trans Golgi side. The trans Golgi network (TGN) is a central place of molecule sorting, and packaging of cargo molecules into vehicles for transport to the final intra or 
extracellular destinations, where the molecules eventually exert their specific functions, such as organelles of the lysosomal system, diverse domains of the plasma membrane, and the extracellular space. At all levels of the biosynthetic-secretory route, anterograde transport of membranes and cargo is counterbalanced by retrograde traffic (for review Sannerud et al. 2003). This is necessary for several reasons, which include the retrieval of molecules that have escaped from the sites of their specific functions, for membrane balance and the maintenance of the functional integrities of organelles and compartments along the secretory route and repeated use of molecules, and molecule repair. Major antero-retrograde traffic cycles are located at the pre-Golgi junction between the ER, the intermediate compartment, and the Golgi apparatus, as well as at the post-Golgi junctions between the TGN, early and late endosomes, and plasma membrane. Within the Golgi apparatus stacks, anterograde transport is assumed to be counterbalanced by retrograde traffic as well. Internalized molecules have been shown to travel along retrograde biosynthetic pathways (e.g. Gonatas et al. 1983; Pavelka et al. 1998; Vetterlein et al. 2002; Volz et al. 1995), and physiologic retrograde routes are misused by harmful substances to reach the sites of their specific toxic effects (e.g. Pelham et al. 1992; Rapak et al. 1997; Sandvig et al. 1991, 1992, 2002; for review Sandvig and van Deurs 2002, 2005). Since the early report in 1992 by Kirsten Sandvig and colleagues, who for the first time showed that along such pathways toxins could be transported en route from the plasma membrane into early compartments of the biosynthetic-secretory system, such retrograde trails of toxins are at the center of cell biologic and medical research.

For both the cell physiologic retrograde routes, and misused pathways, knowledge about molecular machineries, and insights into regulatory mechanisms are increasing rapidly (e.g. Gokool et al. 2007; Mari et al. 2008; Popoff et al. 2007; Wälchli et al. 2008; Yamane et al. 2007; for review Bonifacino and Rojas 2006; Sannerud et al. 2003). In immuno and fine structural analyses, multiple fine details of the compartments, structures and complex architectures involved have been visualized (e.g. Mari et al. 2008; Marsh 2005; Mogelsvang and Howell 2006; Mogelsvang et al. 2004; Pavelka 2007; Pavelka et al. 1998; Vetterlein et al. 2002, 2003). However, there still exists a considerable lack in understanding the mechanisms involved and uncertainties in the interpretations of individual results obtained by molecular biologic and genetic investigations on one hand, and morphologic findings on the other hand. Well known functional processes yet cannot be exactly attributed to concrete defined compartments, and vice versa, the functional implications of multiple structures and architectures need to be clarified. There is a strong need to bring together the biochemical, molecular biological, genetic, morphologic, immuno-cytochemical, and fine structural results.

\section{Retrograde traffic in cell physiology}

Anterograde transport in the secretory route is accompanied and counterbalanced by retrograde traffic at each section of the secretory route, including pre- and post-Golgi areas, and presumably at the level of the stacks of Golgi cisternae as well. The diverse retrograde routes and cycles cannot be seen separately. There exist similarities in the mechanisms and machineries, close relationships, and mutual influences.

\section{Retrograde Golgi-to-ER traffic and pre-Golgi circuits}

By retrograde Golgi apparatus-to-ER traffic, ER-resident luminal and membrane proteins are retrieved (Munro and Pelham 1987; Semenza et al. 1990), and membrane proteins, including the cargo receptor ERGIC-53 (Appenzeller et al. 1999; Schweizer et al. 1988), and Golgi-resident proteins, such as glycosyltransferases, recycle (Lee et al. 2004; Lippincott-Schwartz et al. 1990; Storrie et al. 1998; Storrie 2005). It is evident that multiple retrograde traffic routes work in parallel in order to retrieve molecules to the ER, and cycle proteins and lipids between ER and Golgi apparatus. The first retrograde Golgi-to-ER pathway described was the KDEL-receptor mediated transport of luminal ER proteins (Lewis and Pelham 1990; Munro and Pelham 1987; Semenza et al. 1990), which following the export out of the ER together with the flow of multiple other proteins destined for transport to other destinations have to be retrieved to their sites of functions in the ER. This traffic, as well as the transport of type-I transmembrane proteins bearing the double-lysin motif signal (Letourneur et al. 1994) is mediated by COPI-coated vesicles (Nickel and Wieland 2002). The retrieval of escaped ER-proteins takes place most efficiently from the ER-Golgi intermediate compartment (ERGIC) but can occur from successive Golgi apparatus compartments up to the TGN as well. Luminal acidification, and calcium concentration in the lumina of the respective compartments have been suggested to be regulatory factors (reviewed in Sannerud et al. 2003).

Furthermore, COPI-independent transport machineries act in Golgi-to-ER retrograde traffic (Johannes and Goud 2000). Such routes are known to involve Rab6 GTPases (Girod et al. 1999; Storrie 2005; White et al. 1999), key regulators of intracellular membrane traffic (Hammer and $\mathrm{Wu}$ 2002; Stenmark and Olkkonen 2001; Zerial and McBride 2001). Three different isoforms are known, Rab6A, Rab6A', an alternatively spliced variant of Rab6A (Echard et al. 2000), and the brain-specific Rab6B (Wanschers et al. 2007). Recently, it has been shown that Rab6A and Rab6A' perform different non-overlapping functions in cells, and the Rab6A' isoform is shown mainly regulating the COPI-independent retrograde pathway to the ER (Del Nery et al. 
2006). Rab6A GTPases interact with a subunit of the dynein-dynactin complex, and transport compartments move between Golgi apparatus and ER bidirectionally along the microtubules (Matanis et al. 2002; Short et al. 2002). COPI-independent Rab6A-dependent retrograde pathways are used by Golgi apparatus-resident proteins, such as glycosyltransferases, which cycle continuously between the Golgi apparatus and ER (Martinez et al. 1997; Rhee et al. 2005; Storrie 2005; Storrie et al. 1998).

\section{Retrograde traffic within the Golgi apparatus}

In the anterograde biosynthetic-secretory traffic, newly synthesized molecules arriving from the ER and ERGIC are taken up into the Golgi apparatus, visit cisternae of the stacks to be modified in well known subsequent steps, and are sorted to different further destinations at the trans side and TGN. Since decades, it is well established that the stacks of Golgi cisternae are subcompartmentalized into separate functional spaces, in each of which defined sets of enzymes are active, and collaborate in performing specific modifications of the molecules that visit the respective cisternae, e.g. perform changes of the sugar chains of the glycoconjugates, such as secretory and plasma membrane glycoproteins, enzymes of the lysosomal system, and lysosomal membrane constituents (Berger 1985; Farquhar and Palade 1998; Glick 2000; Pavelka 1987; Puthenveedu and Linstedt 2005; Rambourg and Clermont 1997; Roth 1997; Storrie 2005). It is assumed that the cisternae of the Golgi apparatus stacks are visited by the molecules to be modified, and there occurs a flow of membranes and contents across the stacks. However, at present, it is not clear, how in the dynamics of the flow the Golgi apparatus subcompartmentalization, which ensures effective glycosylation and other processing in the secretory pathway, is maintained. Conflicting results make interpretations complicated but there exist indications that retrograde transport of membrane constituents, such as the subcompartment-specific glycosyltransferases, is involved. The question how, and even whether, newly synthesized membrane and cargo proteins traverse the stacked Golgi cisternae, is a major point of debate. Several models are discussed, suggesting either an anterograde transport via vesicles, or anterograde flow by progression of the cisternae themselves, or by tubular connections between the cisternae, or by a signal-mediated temporary opening of channels connecting adjacent cisternae (Kartberg et al. 2005; Malhotra and Mayor 2006; Marsh and Howell 2002; Marsh et al. 2004; Mironov et al. 2005; Pelham and Rothman 2000; Puthenveedu and Linstedt 2005; Rodriguez-Boulan and Müsch 2005; Sallese et al. 2006; Storrie 2005, Trucco et al. 2004). Contradictory results also concern the retrograde traffic, which at least in the "cisternae progression model" is required for mainte- nance of the specific subcompartments. COPI-coated vesicles, also being involved in the retrograde Golgi-to-ER traffic (see the previous chapter), have been proposed as the candidates for retrograde intra-Golgi traffic but the results are conflicting (summerized by Rabouille and Klumperman 2005), and alternative mechanisms are considered as well, such as traffic across tubular connections between the Golgi cisternae (Marsh et al. 2004; Trucco et al. 2004). The retrograde transport and the cycling of Golgi-resident glycosyltransferases between Golgi apparatus and ER have been shown to be functionally connected with the maintenance of the structure of the Golgi apparatus (Starr et al. 2007; Storrie 2005). Recently, it has been shown that the Rab6binding protein TMF (TATA element modulatory factor), which is involved in the Rab6-dependent retrograde transport processes both from endosomes to the Golgi apparatus, and from the Golgi apparatus to the ER, via its cytoplasmic region is implicated in the retention of $\mathrm{N}$-acetylgalactosaminyltransferase-2 (Yamane et al. 2007).

\section{Retrograde plasma membrane-to-Golgi traffic and post-} Golgi circuits

In part comparable with the pre-Golgi retrograde routes, post-Golgi retrograde traffic on one hand represents a backward flow that counterbalances forward flow by anterograde traffic to the final destinations of newly synthesized molecules to the plasma membrane, extracellular space, secretory granules, endosomes, or lysosomes. Post-Golgi retrograde trafficking concerns TGN-resident proteins, such as TGN38, and receptors involved in the sorting of newly synthesized molecules of the trans Golgi apparatus and TGN to their specific sites of action. This transport is bidirectional; the receptors recycle to the TGN to be reused in further rounds, possibly also being modified or repaired (Bonifacino and Rojas 2006; Rohn et al. 2000; Snyder and Rogers 1985; Volz et al. 1995). Best-studied examples are the cation-independent and the cation-dependent mannose6-phosphate receptors (CI- and CD-MPR; Ghosh et al. 2003). Other recycling proteins are the multi-ligand receptor sortilin (Mari et al. 2008), TGN38 (Banting and Ponnambalam 1997; Ghosh et al. 1998; Stanley and Howell 1993), GPP130 and GP73 (Puri et al. 2002), processing enzymes, such as the transmembrane endoproteases furin and carboxypeptidase D (Molloy et al. 1999; Varlamov and Fricker 1998), and SNAREs (soluble $N$-maleimide-sensitive fusion protein /NFS/ attachment protein receptor; Hettema et al. 2003; Hong 2005). At least, two independent retrograde routes from early endosomes to the TGN exist involving specific components of the Rab and SNARE machineries. One leads to the TGN via late endosomes (Barbero et al. 2002; Carrol et al. 2001; Lombardi et al. 1993; Mallet and Maxfiled 1999); the other one is a direct 
route from early and/or recycling endosomes to the TGN, thus bypassing late endosomes (Mallard et al. 1998, 2002). During the past years, insights into the regulatory mechanisms of retrograde traffic from endosomes to the TGN considerably increased. Multiple constituents of the molecular transport machineries have been characterized and their roles specified; these include Rab9 and TIP47 (tailinteracting protein $47 \mathrm{kDa}$; Diaz et al. 1997), PACS1 (phosphofurin acidic cluster sorting protein 1) and AP-1 (Crump et al. 2001; Meyer et al. 2000), EpsinR (Saint-Pol et al. 2004), the t-SNAREs syntaxin 16 and 5 (Amessou et al. 2007), and constituents of the retromer complex with the two subcomplexes, a membrane-bound coat that consists of the phosphinositide binding proteins Sorting nexin 1 and possibly Sorting nexin 2, and the cargo-binding proteins Vps26, Vps29, and Vps35 (Arighi et al. 2004; Gokool et al. 2007; Popoff et al. 2007; Restrepo et al. 2007; Rojas et al 2007; Seaman et al. 1998; Seaman 2004, 2005; for review Bonifacino and Rojas 2006). Clathrin and the retromer complex are suggested to function in consecutive retrograde sorting steps on early endosomes (Popoff et al. 2007).

There exist several different carrier compartments for retrograde endosome-to-TGN traffic that can form at the same vacuolar early endosome (Mari et al. 2008): tubular sorting endosomes (Peden et al. 2004), and tubular endosomal networks (Bonifacino and Rojas 2006), and the endosome-to-TGN carriers (Mari et al. 2008). The tubular endosomal network (TEN) is connected to vacuolar early endosomes, which exhibit bilayered coats composed of clathrin and Hrs (hepatocyte-growth-factor-regulated tyrosine kinase substrate) thought to contain the ESCRT machinery that targets proteins to the intraluminal vesicles, thus being sorted to the multivesicular-late endosomallysosomal route (Hurley and Emr 2006; Sachse et al. 2002). The vacuolar endosomal part is suggested to receive endocytic cargo from the plasma membrane on one hand, and biosynthetic cargo, e.g. lysosomal enzymes, from the TGN on the other hand; it progressively becomes acidic, leading to the release of the cargo from the receptors. It is proposed that the vacuolar endosomal region matures into late endosomes, whereas from the TEN-region, cargos are sorted to different destination, such as to the TGN and Golgi apparatus along the retrograde route but also to different regions of the plasma membrane for recycling and transcytosis, and to specialized storage compartments, such as melanosomes. The TEN is equipped with different transport machineries including the retromer. It is considered that the pericentriolar endocytic recycling compartment (Ghosh et al. 1998; Maxfield and McGraw 2004; Ullrich et al. 1996) could be a specialized subdomain of TEN. With respect to its central sorting role, TEN is proposed to represent a "mirror image" of the TGN (Bonifacino and Rojas 2006). A possibly comparable endocytic trans-Golgi network has been shown to develop after internalization of wheat germ agglutinin (WGA; Pavelka et al. 1998; Vetterlein et al. 2002; Figs. 1, 2). Recently, a novel class of carriers, the endosome-toTGN carriers (ETCs), has been characterized (Mari et al. 2008). These carriers transport mannose-6-phosphate receptors and sortilin; they are dependent on the presence of sorting nexin 1 (SNX1), and show unique structures appearing as non-branched tubules and vesicles, clearly different from the tubular sorting endosomes (Peden et al. 2004) and tubular networks (Bonifacino and Rojas 2006).

\section{Retrograde traffic of internalized molecules}

The plasma membrane-endosome-TGN pathway used by plasma membrane proteins for reentry into the biosynthetic system for reuse, or modification and repair (Snyder and Rogers 1985; Volz et al. 1995; reviewed in Bonifacino and Rojas 2006) also opens the secretory pathway for entry of extracellular ligands, including harmful substances, such as bacterial and plant toxins (for review Sandvig and van Deurs 2005), and provides tracks for drug delivery to the interior of cells (for review Tarrago-Trani and Storrie 2007).

\section{Retrograde routes of lectins and toxins}

Since more than two decades, it is known that lectins, and bacterial and plant toxins, such as the Shiga and Cholera toxins, the Pseudomonas exotoxin A, and ricin, utilize the retrograde routes within the cells to travel to the TGN and Golgi apparatus, ER, and cytosol (e.g. Gonatas et al. 1983, Sandvig and Brown 1987; van Deurs et al. 1986, 1987). Sandvig et al. (1992) were the first, who showed that Shiga toxin is transported from the cell surface en route to the endoplasmic reticulum. Shiga toxin consists of an enzymatically active A-subunit that is noncovalently linked to a pentamer of B-chains. The latter binds to the glycosphingolipid Gb3, and mediates the toxin's transport. Following internalization, the toxin is transported to early endosomes, sorted to the TGN and Golgi apparatus, and further transported to the ER, from where after cleavage the A-subunit is retrotranslocated to the cytosol, the site where it exerts its toxic action by inactivation of ribosomes, and inhibition of protein synthesis (Johannes and Goud 1998, 2000; Sandvig and van Deurs 1994, 1996, 2002, 2005). It is well established that different uptake mechanisms are used, and there exists not only one route to the endoplasmic reticulum but different retrograde pathways may be traveled by different toxins, and trafficking of one class of toxin is not limited to one route, e.g. Pseudomonas exotoxin A has been shown to travel to the endoplasmic reticulum along multiple path- 


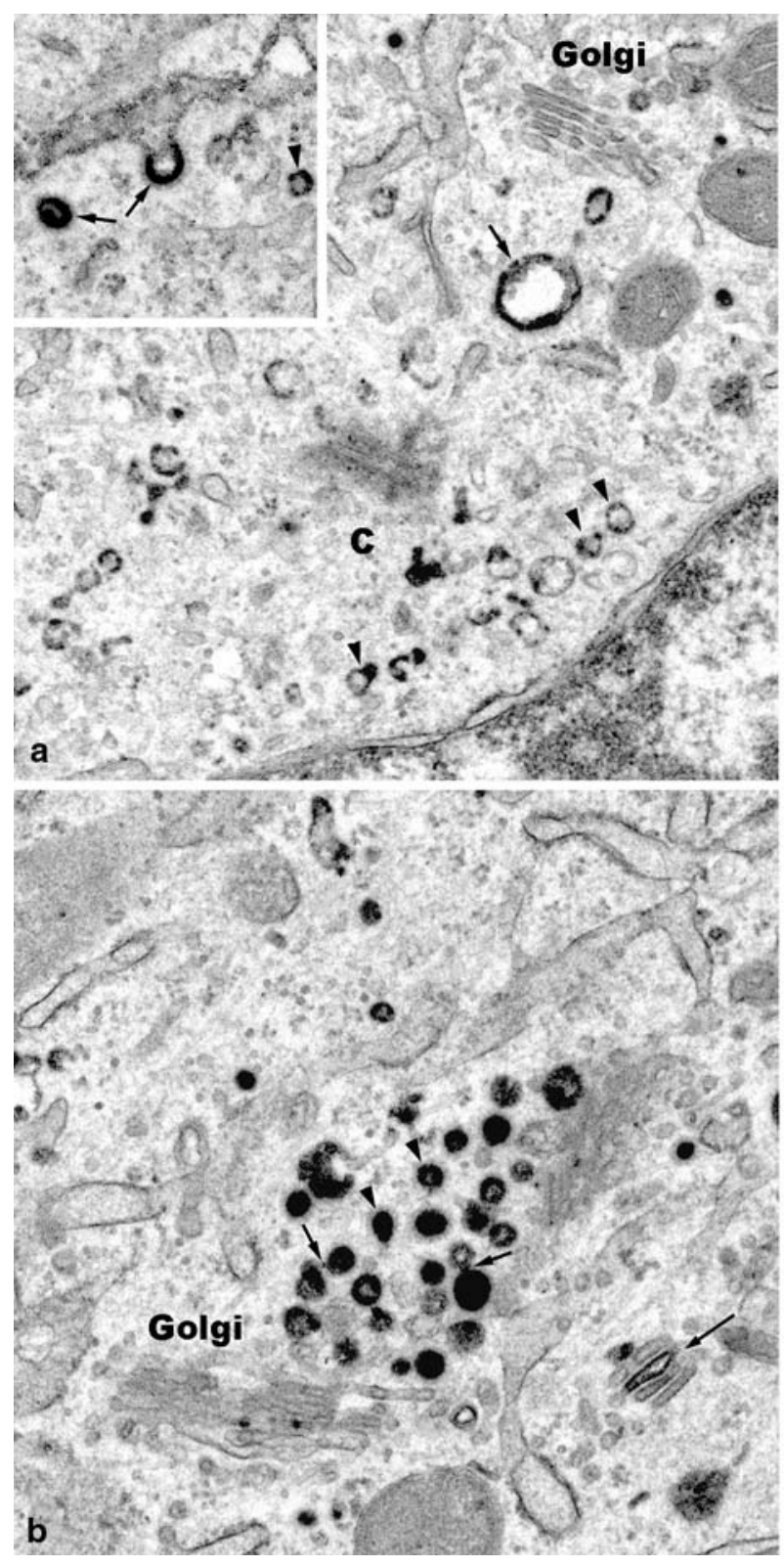

Fig. 1 The Golgi apparatus reorganizes during endocytosis of WGA within a period of $30 \mathrm{~min}$. a insert: The insert shows WGA-HRP reaction products concentrated in a clathrin-coated pit, and a coated vesicle (arrows), as well as lining the membrane of a small uncoated vesicle (arrowhead). $\times 35,000$. a Small endosomes (arrowheads), and a large vacuolar endosome (arrow) are apparent in the cytocentre (c), and close to a small Golgi apparatus stack (Golgi). A distinct TGN is not visible. $\times 30,000$. b Globular early endosomes are accumulated close to the trans side of Golgi apparatus stacks (Golgi); some of the endosomes are covered with clathrin coats (arrowheads); partly, they exhibit WGA reaction products attached to the membranes, partly contained within the lumina. Some of endosomes appear to contact each other, and fine bridges are visible (short arrows). WGA reactions

ways (Smith et al. 2006). There also appears to be fundamental differences between the endosomal sorting into the retrograde pathway to the TGN of Shiga and Cholera toxins (Bujny et al. 2007; Chinnapen et al. 2007; Feng et al. 2004;

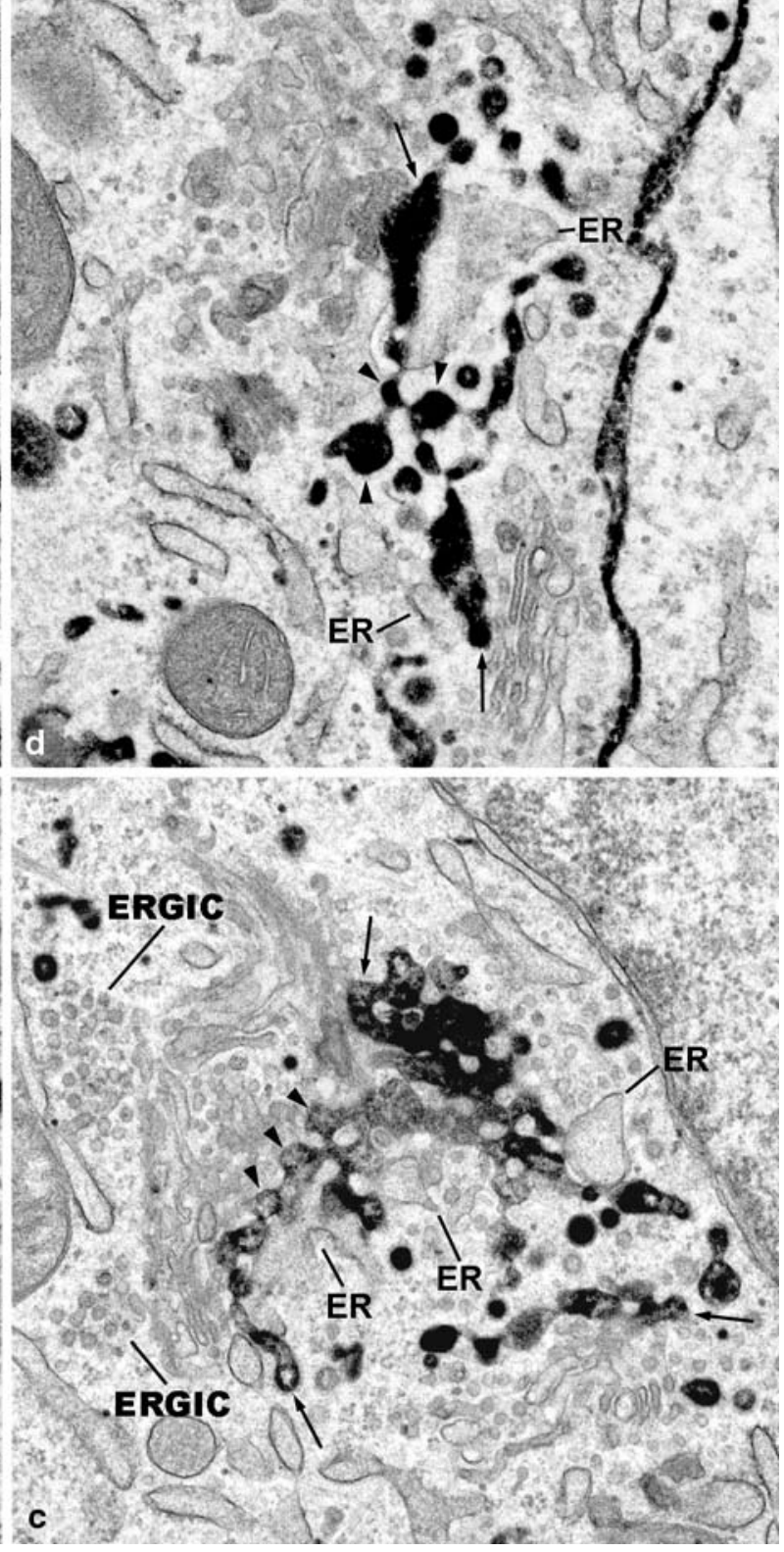

are apparent within the cisternae of a small Golgi apparatus stack (large arrow). $\times 31.500$. c A network, an endocytic trans Golgi network (endocytic TGN), is apparent consisting of interconnected globular pieces (arrowheads) that resemble the earlier globular endosomes. Again here, the WGA reaction products are either attached to the membranes, or fill the lumina. Parts of this endocytic TGN are attached to stacks of Golgi cisternae at their trans sides (arrows), and are associated with trans Golgi ER. At the cis side, ER-Golgi-intermediate compartments $(E R G I C)$ are visible. $\times 28,000$. d Endocytic TGN consisting of interconnected globular pieces (arrowheads) and filled with WGA reaction products are partly attached to Golgi apparatus stacks ( $\mathrm{ar}$ rows), and associated with trans Golgi ER. $\times 32,000$

Massol et al. 2004; Torgersen et al. 2001). Multiple details concerning different uptake mechanisms, and retrograde traffic of Shiga toxin and ricin have been elucidated during the past years (e.g. Amessou et al. 2007; Garred et al. 1995; 


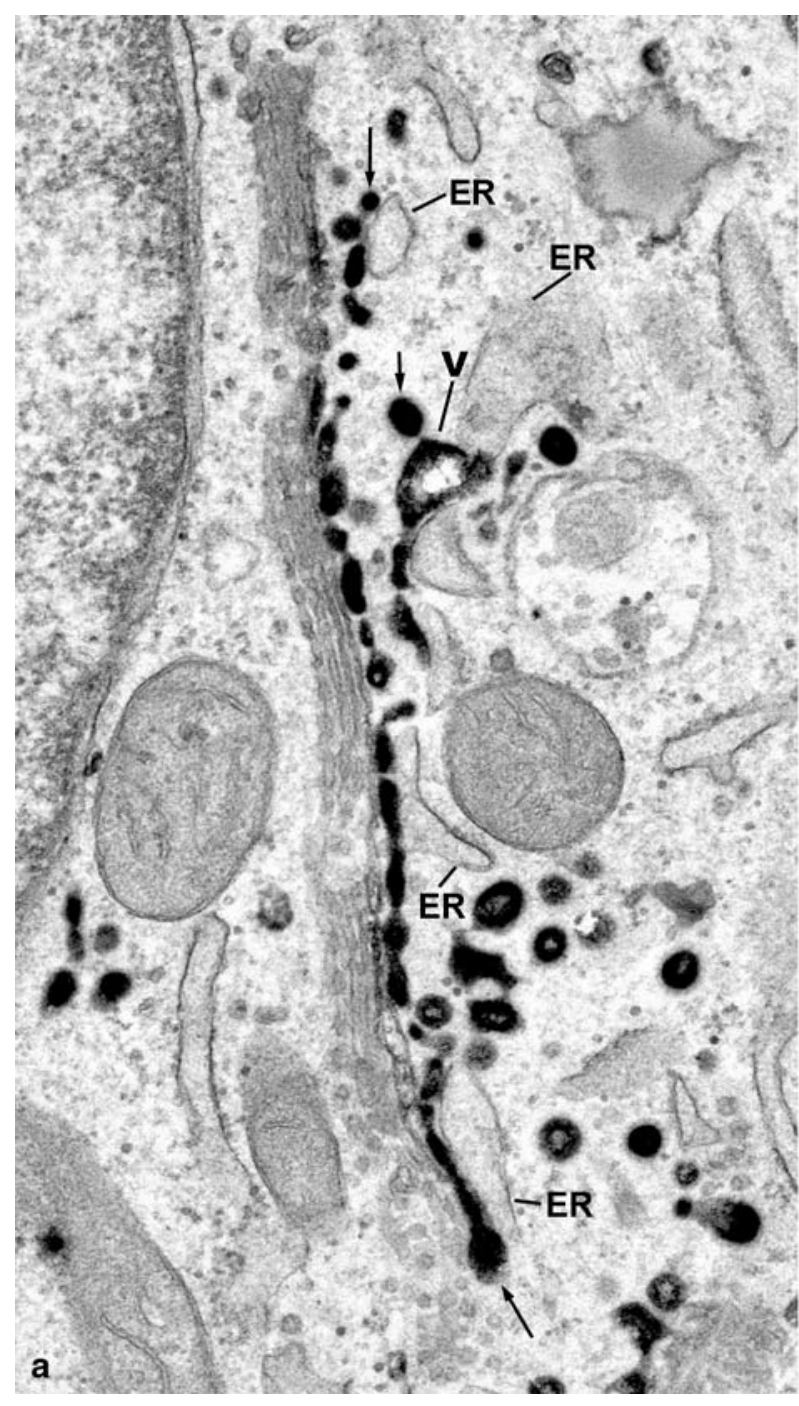

Fig. 2 Portions of the endocytic TGN are integrated in the Golgi apparatus stacks a The WGA-labeled endocytic TGN (long arrows) represents an integrated part of this Golgi apparatus stack, and is closely associated to the transmost Golgi cisterna at one side, and with trans Golgi ER at the opposite side. One large vacuolar part ( $V)$ of the endo-

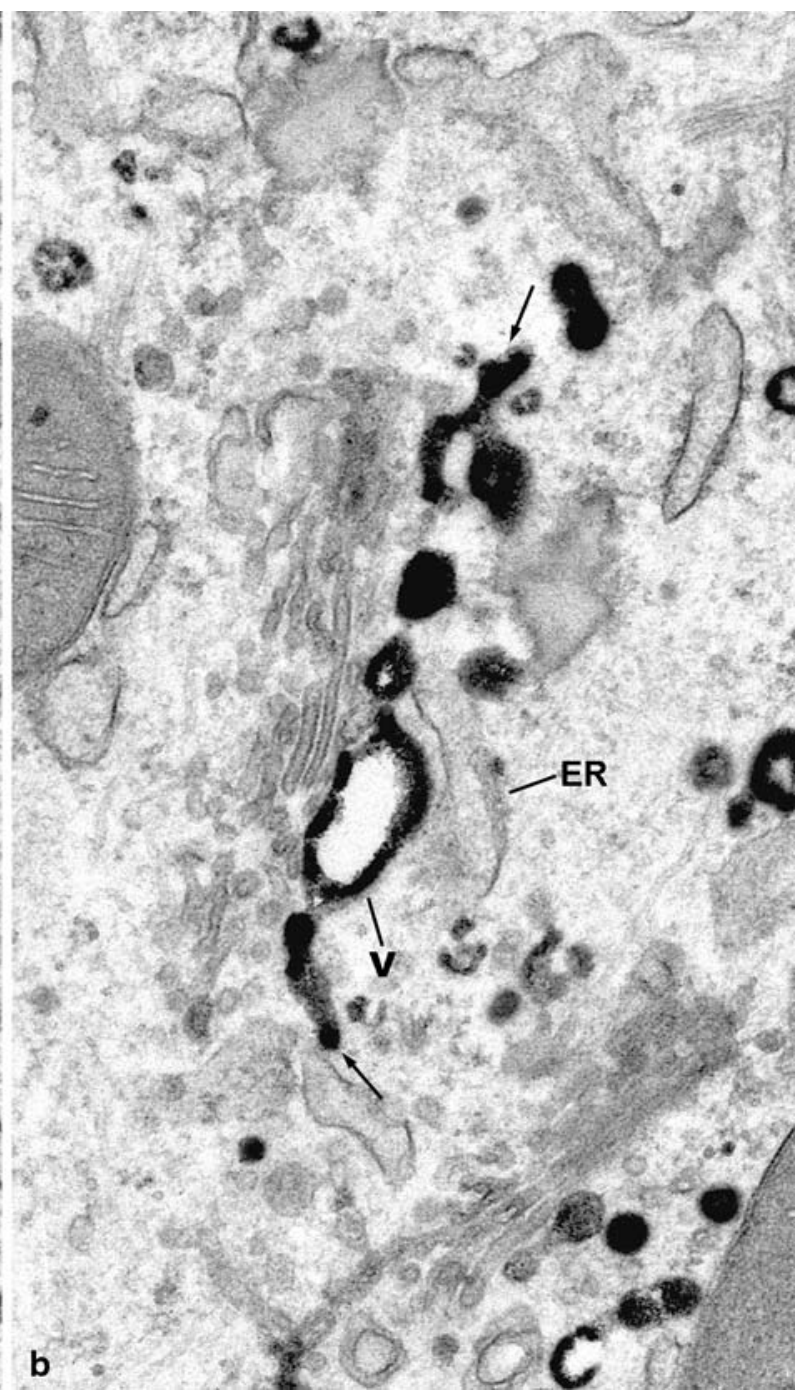

cytic TGN is visible; some of the globular pieces of the endocytic TGN are covered with clathrin coats (short arrow). $\times 35,000$. b The endocytic TGN (arrows) consists of globular pieces, and a large vacuole part $(V)$, which here is attached to the Golgi apparatus stack. $\times 44,000$
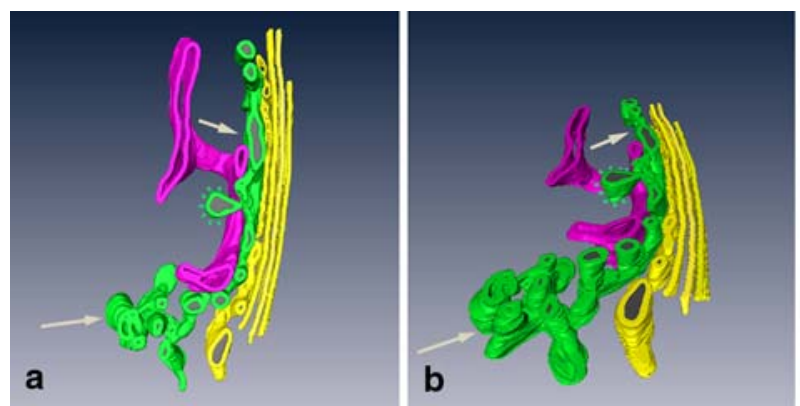

Fig. 3 a-d This 3D-model of a Golgi apparatus stack containing integrated endocytic TGN, has been formed according to the data of an electron tomography tilting series. The model is shown from different sides. The endocytic TGN (green) consists of a free portion (long arrows), and another portion integrated in the stack (short arrows), and

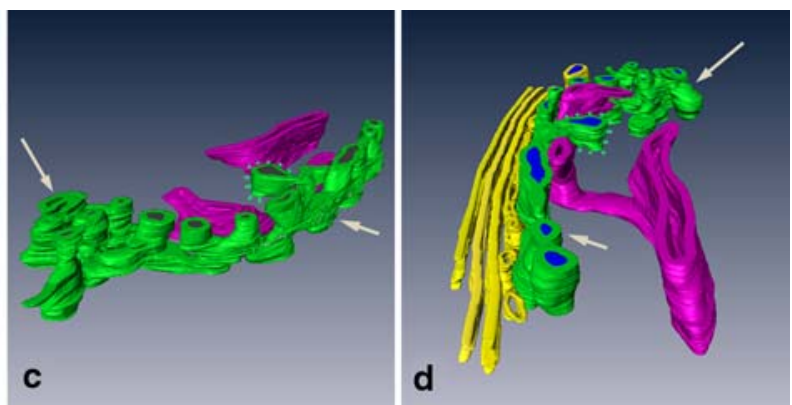

is closely associated with trans Golgi ER (red). In both the free and the Golgi-associated portions, globular elements are visible. Stacked Golgi cisternae are shown in yellow. In c, the stacked Golgi cisternae are removed. Spikes mark clathrin coats 
Grimmer et al. 2005, 2006; Johannes et al. 1997; Lauvrak et al. 2004, 2006; Mallard et al. 1998; Rapak et al. 1997; Römer et al. 2007; Skanland et al. 2007; SlominskaWojewodzka et al. 2006; Tai et al. 2004; Torgersen et al. 2007; Utskarpen et al. 2006, 2007; Yoshino et al. 2005). A key compartment is the early endosome (see previous chapter), from where internalized molecules, are either recycled to the plasma membrane to be reused, or sorted to the late endosomal pathway and to the lysosomes to be degraded, or transferred to a direct pathway to the TGN, travelled by endogenous proteins, like the mannose-6-phosphate receptors (for review Bonifacino and Rojas 2006). It is the latter route that is travelled by Shiga toxin and ricin. For efficient transport of Shiga toxin from early endosomes to the TGN and Golgi apparatus, the retromer complex is required (Bujny et al. 2007; Popoff et al. 2007; Utskarpen et al. 2007). The ricin endosome-to-TGN and Golgi traffic has been shown to be facilitated by depletion of sphingolipid (Grimmer et al. 2006), and to be dependent on Rab6A and Rab6A' (Utskarpen et al. 2006), which are also regulators in pre-Golgi circuits (see previous chapter). The syntaxins 5 and 16 being involved in retrograde transport of mannose6-phosphate receptors, also are necessary for efficient retrograde traffic of Shiga toxin, as well as for trafficking into the cells of ricin and cholera toxin (Amessou et al. 2007). In the center of interest are the regulatory roles of phosphoinositides (for review De Matteis and Godi 2004), and the importance of signaling (Pelkmans et al. 2005; Perret et al. 2005; von Zastrow and Sorkin 2007). Recently, it has been demonstrated that retrograde traffic of Shiga toxin and ricin are phosphoinositide-regulated (Skanland et al. 2007; Utskarpen et al. 2007). The phosphoinositide-binding proteins sorting nexins 1 and 2, being part of the retromer complex (Seaman 2004, 2005), are necessary for efficient transport of Shiga toxin to the Golgi apparatus (Bujny et al. 2007; Popoff et al. 2007; Utskarpen et al. 2007). Sorting nexins have been shown to be in crosstalk with the phosphatidylinositol (PI) 3-kinase hVps34; it is proposed that hVps34 produces a specific PI(3)P pool needed for the localization of sorting nexins on endosome vesicles, which in turn is required for retrograde endosome-to-Golgi traffic of ricin (Skanland et al. 2007).

Shiga toxin is an active player in its own transport mediating both internalization, and intracellular transport. Upon binding to the plasma membrane or entry into the cells, it is able to trigger signaling cascades (Ikeda et al. 2000; Lauvrak et al. 2006; Wälchli et al. 2008). Shiga toxin activates the tyrosine kinase Syk, by which clathrin phosphorylation and uptake of Shiga toxin is induced (Lauvrak et al. 2006). Protein kinase $\mathrm{C} \delta$ is specifically activated by Shiga toxin regulating endosome-to-Golgi transport (Torgersen et al. 2007). Evidence is provided for activation of a signaling cascade that involves a crosstalk between $\mathrm{Ca}^{2+}$ and the MAP kinase p38; it is suggested that Shiga toxin, by modifying $\mathrm{Ca}^{2+}$ homeostasis, recruits $\mathrm{p} 38$ to endosomes for regulation of transport to the Golgi apparatus (Wälchli et al. 2008).

The entry of internalized molecules into the secretory pathway at the TGN and Golgi apparatus level is a major event influencing further retrograde traffic to the ER and cytosol. Although it is well established, and has been shown ultrastructurally very early for several toxins, that transport to the TGN and Golgi apparatus is followed by uptake into cisternae of the Golgi apparatus stacks (e.g. Sandvig et al. 1992; van Deurs et al. 1987), the involved mechanisms are still poorly understood. A detailed ultrastructural analysis has been undertaken using a HepG2 hepatoma cell model, and uptake of wheat germ agglutinin labeled with horseradish peroxidase (WGA-HRP; Pavelka et al. 1998; Pavelka 2007; Vetterlein et al. 2002).

Wheat germ agglutinin is an $\mathrm{N}$-acetyl-glucosamine and sialic acid-specific lectin, which is known for many years to be transported to the Golgi apparatus in retrograde direction (e.g. Gonatas et al. 1977; Stieber et al. 1984); it is also used in connection with the developments of drug delivery systems (Lochner et al. 2003; Weissenböck et al. 2004). WGA reacts with numerous binding sites at the cell surface, and is taken up in large amounts, thus mimicking normal situations in cells, and here particularly reflecting the functions of hepatocytes in the liver tissue. HepG2 hepatoma cells are especially well suited for these studies, since prior to, and in the initial phases of WGA endocytosis, the Golgi apparatus mainly consists of small inconspicuous stacks of cisternae (Fig. 1a), and the changes and reorganizations of the Golgi apparatus during WGA-endocytosis are clearly visible (Figs. 1, 2, 4). Briefly, the results show that internalized WGA, following internalization via clathrin-coated vesicles (Fig. 1a insert) and possibly other mechanisms as well, is rapidly transported to the Golgi apparatus, and induces dramatic Golgi reorganizations. Early globular endosomes accumulate at the trans Golgi side (Fig. 1b) and a network is formed, an endocytic trans-Golgi network (endocytic TGN) that consists of interconnected globular pieces (Fig. 1c), which in dimensions and shapes resemble the earlier globular endosomes (Fig. 1b). In these compartments, the WGA reaction products in part detach from the limiting membranes, and fill the lumina (Fig. 1b, c, d) indicating that the luminal milieu is changing. Portions of the endocytic TGN in close association with trans-Golgi ER, attach to trans Golgi cisternae (Fig. 1c, d), thus becoming integrated parts of the Golgi apparatus stacks (Figs. 2a, b, 4a; various views of a 3D-model are presented in Fig. 3a-d). The trans-Golgi attachment of the endocytic TGN leads to interconnections of the small Golgi stacks (Figs. 1c, d, 4b), and causes the formation of Golgi apparatus ribbons. Concomitantly, and in part prior to the formation of an endocytic TGN, internalized WGA appears within cisternae of 


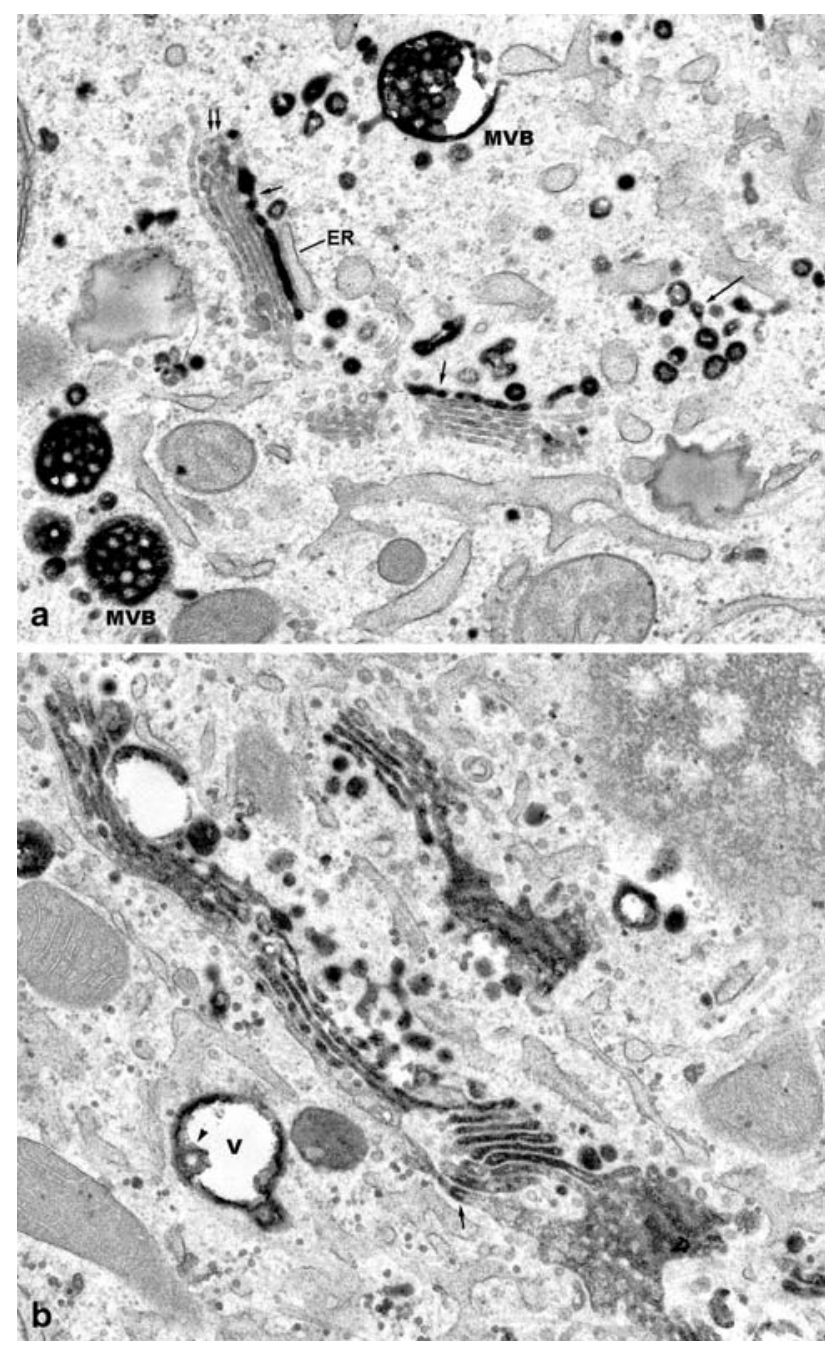

Fig. 4 WGA is taken up into the stacked Golgi cisternae a Free portions (long arrows), and Golgi-integrated portions (short arrows) of the WGA-reactive endocytic TGN are visible. Fine WGA reactions also are apparent at confined regions of some of the stacked Golgi cisternae (double arrow). Several multivesiculated bodies $(M V B)$ are densely filled with WGA-reaction products, and show domains, where tubular and vesicular transport carriers are formed. $\times 20,000$. b A Golgi ribbon is visible, in which the individual stacks of cisternae are interconnected at the cis, as well as at the trans side. Most of the stacked Golgi cisternae are densely filled with WGA reaction products; others show reactions at limited regions (arrow). At the right lower corner, connections of medial cisternae with the cis-most cisterna of the same stack, and of other stacks are shown. In a vacuolar endosome $(V)$, WGA reaction products are attached to the limiting membrane, and to an intra-vacuolar vesicle (arrowhead). $\times 23,000$

Golgi apparatus stacks (Figs. 1b, d, 4a). Stacks that contain high amounts of WGA within the lumina of all the cisternae are mainly found at later periods of WGA endocytosis, e.g. after 45-60 min (Fig. 4b). Very seldom, internalized WGA can be localized within the ER cisternae. At all periods of WGA endocytosis, internalized WGA appears within multivesiculated bodies (Fig. 4a, b), indicating that internalized
WGA not only trafficks into the Golgi apparatus but is sorted to the late endosomal-lysosomal pathway as well.

The detailed knowledge of these endocytosis-induced Golgi reorganizations has been used to develop a precise time schedule for regulated retrograde transport of WGA into the endoplasmic reticulum by treatment with Brefeldin A (Vetterlein et al. 2003). However, multiple questions are open, which concern the mechanisms of formation of the endocytic TGN, and its attachment to the Golgi stacks, the delivery of cargo, and uptake of membranes, interactions of transport carriers with Golgi subcompartments, mechanisms of retrograde transport within the Golgi apparatus stacks, signaling and the role of contact points, the importance of lipid transfer (De Matteis et al. 2007; Hanada et al. 2007), and possible direct endocytic TGN-to-ER traffic via trans-Golgi associated ER. Of particular interest are questions, as to whether secretory anterograde flow influences retrograde traffic, and vice versa, as to whether retrograde flow influences Golgi apparatus size and localization, and whether the formation of Golgi ribbons by retrograde flow is comparable with the formation of Golgi ribbons by input of membrane derived from the ER (Marra et al. 2007).

\section{Concluding remarks}

In future studies, it will be important to correlate the detailed fine structural findings with the molecular biologic and genetic results on the machineries and regulatory mechanisms of retrograde traffic (e.g. Amessou et al. 2007; Bonifacino and Rojas 2006; De Matteis et al. 2007; Hanada et al. 2007; Levine and Loewen 2006; Marra et al. 2007; Missiaen et al. 2007; von Zastrow and Sorkin. 2007; Wälchli et al. 2008). The crucial roles of retrograde traffic in the biosynthetic-secretory route for cellular homeostasis and intoxication of cells, the importance for assessment of effects and side effects of drugs (e.g. Sandoval and Molitoris 2004), and the development of strategies for targeted drug delivery to the interior of cells (El Alaoui et al. 2007; Johannes and Decaudin 2005; Kreitman 2006; Smith et al. 2002; Tarrago-Trani and Storrie 2007; Weissenböck et al. 2004) will be the driving forces.

Acknowledgments The authors cordially thank all the colleagues involved in the work presented in this review, Anita Aichinger, Peter Auinger, Ulrich Kaindl, Jedrzej Kosiuk, Beatrix Mallinger, Claudia Meisslitzer-Ruppitsch, Majid Niapir, Julia Riess, Elfriede Scherzer, Monika Vetterlein, and Christoph Weiss. Parts of the studies were performed within the Associate Membership to the Network of Excellence 3D-EM in cooperation with Wolfgang Baumeister, Jürgen M. Plitzko, and colleagues, Max Planck Institute of Biochemistry, Martinsried, Germany. Parts of the studies were performed in cooperation with Alexander Mironov, Alberto Luini, and colleagues from the Consorzio Mario Negri Sud, S.Maria Imbaro, Italy. 


\section{References}

Appenzeller C, Andersson H, Kappeler F, Hauri H-P (1999) The lectin ERGIC-53 is a cargo transport receptor for glycoproteins. Nat Cell Biol 1:330-334

Amessou M, Fradagrada A, Falguieres T, Lord JM, Smith DC, Roberts LM, Lamaze C, Johannes L (2007) Syntaxin 16 and syntaxin 5 are required for efficient retrograde transport of several exogenous and endogenous cargo proteins. J Cell Sci 120:1457-1468

Arighi CN, Hartnell LM, Aguilar RC, Haft CR, Bonifacino JS (2004) Role of the mammalian retromer in sorting of the cation-independent mannose 6-phosphate receptor. J Cell Biol 165:123-133

Banting G, Ponnambalam S (1997) TGN38 and its orthologues: roles in post-TGN vesicle formation and maintenance of TGN morphology. Biochim Biophys Acta 1355:209-217

Barbero P, Bittova L, Pfeffer SR (2002) Role of Rab9 GTP-mediated vesicle transport from endosomes to the trans-Golgi in living cells. J Cell Biol 156:511-518

Berger EG (1985) Mini-review: how Golgi-associated glycosylation works. Cell Biol Int Rep 9:407-417

Bonifacino JS, Rojas R (2006) Retrograde transport from endosomes to the trans-Golgi network. Nat Rev Mol Cell Biol 7:568-579

Bujny MV, Popoff V, Johannes L, Cullen PJ (2007) The retromer component sorting nexin-1 is required for efficient retrograde transport of Shiga toxin from early endosome to the trans Golgi network. J Cell Sci 120:2010-2021

Carrol KS, Hanna J, Simon I, Krise J, Barbero P, Pfeffer SR (2001) Role of Rab9-GTPase in facilitating receptor recruitment by TIP47. Science 292:1373-1376

Chinnapen DJF, Chinnapen H, Saslowsky D, Lencer WI (2007) Rafting with cholera toxin: endocytosis and trafficking from the plasma membrane to ER. FEMS Microbiol Lett 266:129-137

Crump CM, Xiang X, Thomas L, Gu F, Austin C, Tooze SA, Thomas $\mathrm{G}$ (2001) PACS-1 binding to adaptors is required for acidic cluster motif-mediated protein traffic. EMBO J 20:2191-2201

De Matteis MA, Godi A (2004) PI-loting membrane traffic. Nat Cell Biol 6:487-492

De Matteis MA, Di Campli A, D’Angelo G (2007) Lipid transfer proteins in membrane trafficking at the Golgi complex. Biochim Biophys Acta 1771:761-768

Del Nery E, Miserey-Lenkeil S, Falguieres T, Nizak C, Johannes L, Perez F, Goud B (2006) Rab6A and Rab6A' GTPases play nonoverlapping roles in membrane trafficking. Traffic 7:394-407

Diaz E, Schimmoller F, Pfeffer SR (1997) A novel Rab9 effector required for endosome-to-TGN transport. J Cell Biol 138:283-290

Echard A, Opdam FJ, de Leeuw HJ, Jollivet F, Savelkoul P, Hendriks W, Voorberg J, Goud B, Fransen JA (2000) Alternative splicing of the human Rab6A gene generates two close but functionally different isoforms. Mol Biol Cell 11:3819-3833

El Alaoui A, Schmidt F, Amessuo M, Sarr M, Decaudin D, Florent JC, Johannes L (2007) Shiga toxin-mediated retrograde delivery of a topoisomerase I inhibitor prodrug. Angewandte Chemie-International Edition 46:6469-6472

Farquhar MG, Hauri H-P (1997) Protein sorting and vesicular traffic in the Golgi apparatus. In: Berger EG, Roth J (eds) The Golgi apparatus. Birkhäuser, Basel, pp 63-129

Farquhar MG, Palade GE (1998) The Golgi apparatus: 100 years of progress and controversy. Trends Cell Biol 8:2-10

Feng Y, Jadhav AP, Rodighiero CH, Fujinaga Y, Kirchhausen T, Lencer WI (2004) Retrogarde transport of cholera toxin from the plasma membrane to the endoplasmic reticulum requires the transGolgi network but not the Golgi apparatus in Exo2-treated cells. EMBO 5:596-601

Garred O, van Deurs B, Sandvig K (1995) Furin-induced cleavage and activation of Shiga toxin. J Biol Chem 270:10817-10821
Ghosh RN, Mallet WG, Soe TT, McGraw TE, Maxfield FR (1998) An endocytosed TGN38 chimeric protein is delivered to the TGN after trafficking through the endocytic recycling compartment in CHO cells. J Cell Biol 142:923-936

Ghosh P, Dahms NM, Kornfeld S (2003) Mannose-6-phosphate receptors: new twists in the tale. Nat Rev Mol Cell Biol 4:202-212

Girod A, Storrie B, Simpson JC, Johannes L, Goud B, Roberts LM, Lord JM, Nilsson T, Pepperkok R (1999) Evidence for a COP-Iindependent transport route from the Golgi complex to the endoplasmic reticulum. Nat Cell Biol 1:423-430

Glick BS (2000) Organization of the Golgi apparatus. Curr Opin Cell Biol 12:50-56

Gokool S, Tattersall D, Seaman MNJ (2007) EHD 1 interacts with retromer to stabilize SNX1 tubules and facilitate endosome-to-Golgi retrieval. Traffic 8:1873-1886

Gonatas NK, Kim SU, Stieber A, Avrameas S (1977) Internalization of lectins in neuronal GERL. J Cell Biol 73:1-13

Gonatas NK, Stieber A, Gonatas JO, Mommoi T, Fishman PH (1983) Endocytosis of exogenous GM1 ganglioside and cholera toxin by neuroblastoma cells. Mol Cell Biol 3:91-101

Grimmer S, Ying M, Wälchli S, van Deurs B, Sandvig K (2005) Golgi vesiculation induced by cholesterol occurs by a dynamin- and cPLA2-dependent mechanism. Traffic 6:144-156

Grimmer S, Spilsberg B, Hanada K, Sandvig K (2006) Depletion of sphingolipids facilitates endosome to Golgi transport of ricin. Traffic 7:1243-1253

Hammer JA, Wu XS (2002) Rabs grab motors: defining the connections between Rab GTPases and motor proteins. Curr Opin Cell Biol 14:69-75

Hanada K, Kumagai K, Tomishige N, Kawano M (2007) CERT and intracellular trafficking of ceramide. Biochim Biophys Acta 1771:644-653

Hettema EH, Lewis MJ, Black MW, Pelham HR (2003) Retromer and sorting nexins Snx4/41/42 mediate distinct retrieval pathways from yeast endosomes. EMBO J 22:548-557

Hong W (2005) SNAREs and traffic. Biochim Biophys Acta 1744:493-517

Hurley JA, Emr SD (2006) The ESCRT complexes: structure and mechanism of a membrane trafficking network. Annu Rev Biophys Biomol Struct 35:277-298

Ikeda M, Gunji Y, Yamasaki S, Takeda Y (2000) Shiga toxin activates p38 MAP kinase through cellular $\mathrm{Ca}(2+)$ increase in Vero cells. FEBS Lett 485:94-98

Johannes L, Goud B (1998) Surfing on a retrograde wave: how does Shiga toxin reach the endoplasmic reticulum? Trends Cell Biol 8:158-162

Johannes L, Goud B (2000) Facing inward from compartment shores: how many pathways were we looking for? Traffic 1:119-123

Johannes L, Decaudin D (2005) Protein toxins: intracellular trafficking for targeted therapy. Gene Ther 12:1360-1368

Johannes L, Tenza D, Antony C, Goud B (1997) Retrograde transport of KDEL-bearing B-fragment of Shiga toxin. J Biol Chem 272:19554-19561

Kartberg F, Elsner M, Fröderberg L, Asp L, Nilsson T (2005) Commuting between Golgi cisternae-mind the GAP! Biochim Biophys Acta 1744:351-363

Kreitman RJ (2006) Immunotoxin for targeted cancer therapy. AAPS J 8:E532-E551

Lauvrak SU, Torgersen ML, Sandvig K (2004) Efficient endosome-toGolgi transport of Shiga toxin is dependent on dynamin and clathrin. J Cell Sci 117:2321-2331

Lauvrak SU, Wälchli S, Iversen TG, Slagsvold HH, Torgersen ML, Spilsberg B, Sandvig K (2006) Shiga toxin regulates its entry in a Syk-dependent manner. Mol Biol Cell 17:1096-1109

Lee MC, Miller EA, Goldberg J, Orci L, Schekmann R (2004) Bidirectional protein transport between the ER and Golgi. Annu Rev Cell Dev Biol 20:87-123 
Letourneur F, Gaynor EC, Henneke S, Demolliere C, Duden R, Emr SD, Riezman H, Cosson P (1994) Coatomer is essential for retrieval of dilysine-tagged proteins to the endoplasmic reticulum. Cell 79:1199-1207

Levine T, Loewen C (2006) Inter-organelle contact sites: through a glass, darkly. Curr Opin Cell Biol 18:371-378

Lewis MJ, Pelham HR (1990) A human homologue of the yeast HDEL receptor. Nature 348:162-163

Lippincott-Schwartz J, Donaldson JG, Schweizer A, Berger EG, Hauri H-P, Yuan LC, Klausner RD (1990) Microtubule-dependent retrograde transport of proteins into the ER in the presence of Brefeldin A suggests an ER recycling pathway. Cell 60:821-836

Lochner N, Pittner F, Wirth M, Gabor F (2003) Wheat germ agglutinin binds to the epidermal growth factor receptor of artificial CaCo-2 membranes as detected by silver nanoparticle enhanced fluorescence. Pharma Res 20:833-839

Lombardi D, Soldati T, Riederer MA, Goda Y, Zerial M, Pfeffer SR (1993) Rab9 functions in transport between late endosomes and trans Golgi network. EMBO J 12:677-682

Malhotra V, Mayor S (2006) Cell biology: the Golgi grows up. Nature 441:939-940

Mallard F, Antony C, Tenza D, Salamero J, Goud G, Johannes L (1998) Direct pathway from early/recycling endosomes to the Golgi apparatus revealed trough the study of Shiga toxin-B fragment transport. J Cell Biol 143:973-990

Mallard F, Tang BL, Galli T, Tenza D, Saint-Pol A, Yue X, Antony C, Hong W, Goud B, Johannes L (2002) Early/recycling endosomesto-TGN transport involves two SNARE complexes and a Rab6 isoform. J Cell Biol 156:653-664

Mallet WG, Maxfiled FR (1999) Chimeric forms of furin and TGN38 are transported from the plasma membrane to the trans-Golgi network via distinct endosomal pathways. J Cell Biol 146:345-359

Mari M, Bujny MV, Zeuschner D, Geerts WJC, Griffith J, Petersen CM, Cullen PJ, Klumperman J, Geuze HJ (2008) SNX1 defines an early endosomal recycling exit for sortilin and mannose 6phosphate receptors. Traffic (in press)

Marra P, Salvatore L, Mironov Jr.A, Di Campli A, Di Tullio G, Trucco A, Beznoussenko G, Mironov A, De Matteis MA (2007) The biogenesis of the Golgi ribbon: the roles of membrane input from the ER and of GM130. Mol Biol Cell 18:1595-1608

Marsh BJ (2005) Lessons from tomographic studies of the mammalian Golgi. Biochim Biophys Acta 1744:273-292

Marsh BJ, Howell KE (2002) The mammalian Golgi-complex debates. Nat Rev Mol Cell Biol 3:789-795

Marsh BJ, Volkman N, McIntosh JR, Howell KE (2004) Direct continuities between cisternae at different levels of the Golgi complex in glucose-stimulated mouse islet beta cells. Proc Natl Acad Sci USA 101:5565-5570

Martinez O, Antony C, Pehau-Arnaudet G, Berger EG, Salamero J, Goud B (1997) GTP-bound forms of rab6 induce the redistribution of Golgi proteins into the endoplasmic reticulum. Proc Natl Acad Sci USA 94:1828-1833

Massol RH, Larsen JE, Fujinaga Y, Lencer WI, Kirchhausen T (2004) Cholera toxin toxicity does not require functional Arf6- and dynamin-dependent endocytic pathways. Mol Biol Cell 15:36313641

Matanis T, Akhmanova A, Wulf P, Del Nery E, Weide T, Stepanova T, Galjart N, Grosveld F, Goud B, De Zeeuw CI, Barnekow A, Hoogenraad CC (2002) Bicaudal-D regulates COP I-independent Golgi-ER transport by recruiting the dynein-dynactin motor complex. Nat Cell Biol 4:986-992

Maxfield FR, McGraw TE (2004) Endocytic recycling. Nat Rev Mol Cell Biol 5:121-132

Meyer C, Zizioli D, Lausman S, Eskelinen EL, Hamann J, Saftig P, von Figura K, Schu P (2000) $\mu$ 1A-adaptin-deficient mice: lethal- ity, loss of AP-1 binding and rerouting of mannose-6-phosphate receptors. EMBO J 19:2193-2203

Mellman I, Warren G (2000) The road taken:past and future foundation of membrane traffic. Cell 100:99-112

Mironov AA, Beznoussenko GV, Polishchuk RS, Trucco A (2005) Intra-Golgi transport:a way to a new paradigm? Biochim Biophys Acta 1744:340-350

Missiaen L, Dode L, Vanoevelen J, Raeymaekers L, Wuytack F (2007) Calcium in the Golgi apparatus. Cell Calcium 41:405-416

Mogelsvang S, Howell KE (2006) Global approaches to study Golgi function. Curr Opin Cell Biol 18:438-443

Mogelsvang S, Marsh BJ, Ladinsky MS, Howell KE (2004) Predicting function from structure: 3D structure studies of the mammalian Golgi complex. Traffic 5:338-345

Molloy SS, Anderson ED, Jean F; Thomas G (1999) Bi-cycling the furin pathway: from TGN localization to pathogen activation and embryogenesis. Trends Cell Biol 9:28-35

Munro S, Pelham HR (1987) A C-terminal signal prevents secretion of luminal ER proteins. Cell 48:899-907

Nickel W, Wieland FT (2002) Vesicular transport: the core machinery of COPI recruitment and budding. J Cell Sci 115:3235-3240

Pavelka M (1987) Functional morphology of the Golgi apparatus. Adv Anat Embryol Cell Biol 106:1-94

Pavelka M (2007) Visualization of cellular dynamics. In: Proceeding MCM8, Prague 2008, pp 407-410

Pavelka M, Ellinger A, Debbage P, Loewe C, Vetterlein M, Roth J (1998) Endocytic routes to the Golgi apparatus. Histochem Cell Biol 109:555-570

Peden AA, Oorschot V, Hesser BA, Austin CD, Scheller RH, Klumperman J (2004) Localization of the AP-3 adapter complex defines a novel endosomal exit site for lysosomal membrane proteins. J Cell Biol 164:1065-1076

Pelham HRB, Rothman JE (2000) The debate about transport in the Golgi-two sides of the same coin? Cell 102:713-719

Pelham HRB, Roberts LM, Lord JM (1992) Toxin entry: how reversible is the secretory pathway? Trends Cell Biol 2:183-185

Pelkmans L, Fava E, Grabner H, Hannus M, Haberman B, Krausz E, Zerial M (2005) Genome-wide analysis of human kinases in clathrin- and caveolae/raft-mediated endocytosis. Nature 436:78-86

Perret E, Lakkaraju A, Deborde S, Schreiner R, Rodriguez-Boulan E (2005) Evolving endosomes: how many varieties and why? Curr Opin Cell Biol 17:423-434

Popoff V, Mardones GA, Tenza D, Rojas R, Lamaze C, Bonifacino JS, Raposo G, Johannes L (2007) The retromer complex and clathrin define an early endosomal retrograde exit site. J Cell Sci 120:2022-2031

Puri S, Bachert C, Fimmel CJ, Linstedt AD (2002) Cycling of early Golgi proteins via the cell surface and endosomes upon luminal pH disruption. Traffic 3:641-653

Puthenveedu MA, Linstedt AD (2005) Subcompartmentalizing the Golgi apparatus. Curr Opin Cell Biol 17:369-375

Rabouille C, Klumperman J (2005) Opinion: The maturing role of COPI vesicles in intra Golgi transport. Nat Rev Mol Cell Biol 6:812-817

Rambourg A, Clermont Y (1997) Three-dimensional structure of the Golgi apparatus in mammalian cells. In: Berger EG, Roth J (eds) The Golgi apparatus. Birkhäuser, Basel, pp 37-61

Rapak A, Falsnes PO, Olsnes S (1997) Retrograde transport of mutant ricin to the endoplasmic reticulum with subsequent translocation to the cytosol. Proc.Natl Acad Sci USA 94:3783-3788

Restrepo R, Zhao X, Peter H, Zhang B, Arvan P, Nothwehr SF (2007) Structural features of Vps35p involved in interaction with other subunits of the retromer complex. Traffic 8:1841-1853

Rhee SW, Starr T, Forsten-Williams K, Storrie B (2005) The steadystate distribution of glycosyltransferases between the Golgi appa- 
ratus and the endoplasmic reticulum is approximately 90:10. Traffic 6:978-990

Rodriguez-Boulan E, Müsch A (2005) Protein sorting in the Golgi complex: Shifting paradigms. Biochim Biophys Acta 1744:455-464

Rojas R, Kametaka S, Hafr CR, Bonifacino JS (2007) Interchangeable but essential functions of SNX1 in the association of retromer with endosomes and the trafficking of mannose 6-phosphate receptors. Mol Cell Biol 27:1112-1124

Rohn WM, Rouille Y, Waguri S, Hoflack B (2000) Bi-directional trafficking between the trans-Golgi network and the endosomal/ lysosomal system. J Cell Sci 113:2093-2101

Römer W, Berland L, Chambon V, Gaus K, Windschiegl B, Tenza D, Aly MRE, Fraisier V, Florent JC, Perrais D, Lamaze C, Raposo G, Steinem C, Sens P, Bassereau P, Johannes L (2007) Shiga toxin induces tubular membrane invagination for its uptake into cells. Nature 450:670-675

Roth J (1997) Topology of glycosylation in the Golgi apparatus. In: Berger EG, Roth J (eds) The Golgi apparatus. Birkhäuser, Basel, pp 131-161

Sachse M, Urbé S, Oorschot V, Strous GJ, Klumperman J (2002) Bilayered clathrin coats on endosomal vacuoles are involved in protein sorting towards lysosomes. Mol Biol Cell 13:1313-1328

Saint-Pol A, Yelamos B, Amessou M, Mills IG, Dugast M, Tenza D, Schu P, Antony C, McMahon HT, Lamaze C, Johannes L (2004) Clathrin adaptor EpsinR is required for retrograde sorting on early endosomal membranes. Dev Cell 6:525-538

Sallese M, Pulvirenti T, Luini A (2006) The physiology of membrane transport and endomembrane-based signalling. EMBO J 25:2663-2673

Sandoval RM, Molitoris BA (2004) Gentamycin traffics retrograde through the secretory pathway and is released in the cytosol via the endoplasmic reticulum. J Physiol Renal Physiol 286:F617-F624

Sandvig K, Brown JE (1987) Ionic requirements for entry of Shiga toxin from Shigella dysenteriae 1 into cells. Infect Immun 55:298-303

Sandvig K, van Deurs B (1994) Endocytosis and intracellular sorting of ricin and Shiga toxin. FEBS Lett 346:99-102

Sandvig K, van Deurs B (1996) Endocytosis, intracellular transport, and cytotoxic action of Shiga toxin and ricin. Physiol Rev 76:949-966

Sandvig K, van Deurs B (2002) Membrane traffic exploited by protein toxins. Annu Rev Cell Dev Biol 18:1-24

Sandvig K, van Deurs B (2005) Delivery into cells: lessons learned from plant and bacterial toxins. Gene Ther 12:865-872

Sandvig K, Prydz K, Hansen SH, van Deurs B (1991) Ricin transport in Brefeldin A-treated cells: Correlation between Golgi structure and toxic effect. J Cell Biol 115:971-981

Sandvig K, Garred O, Prydz K, Kozlov J, Hansen SH, Deurs B (1992) Retrograde transport of endocytosed Shiga toxin to the endoplasmic reticulum. Nature 358:510-512

Sandvig K, Grimmer S, Lauvrak SU, Torgersen ML, Skretting G, Deurs B, Iversen TG (2002) Pathways followed by ricin and Shiga toxin into cells. Histchem Cell Biol 117:131-141

Sannerud R, Saraste J, Goud B (2003) Retrograde traffic in the biosynthetic-secretory route: pathways and machinery. Curr Opin Cell Biol 15:438-445

Schweizer A, Fransen JAM, Bächi T, Ginsel L, Hauri H-P (1988) Identification, by a monoclonal antibody, of a $53-\mathrm{kD}$ protein associated with a tubularvesicular compartment at the cis-side of the Golgi apparatus. J Cell Biol 107:1643-1653

Seaman MN (2004) Cargo-selective endosomal sorting for retrival to the Golgi requires retromer. J Cell Biol 165:111-122

Seaman MN (2005) Recycle your receptors with retromer. Tends Cell Biol 15:68-75

Seaman MN, MCCaffery JM, Emr SD (1998) A membrane coat complex essential for endosome-to-Golgi retrograde transport in yeast. J Cell Biol 142:665-681
Semenza JC, Hardwick KG, Dean N, Pelham HR (1990) ERD2, a yeast gene required for the receptor-mediated retrieval of luminal ER proteins from the secretory pathway. Cell 61:1349-1357

Short B, Preisinger C, Schaletzky J, Kopajtich R, Barr F (2002) The Rab6 GTPase regulates recruitment of the dynactin complex to the Golgi membranes. Curr Biol 12:1792-1796

Skanland SS, Wälchli S, Utskarpen A, Wandinger-Ness A, Sandvig K (2007) Phosphoinositide-regulated retrograde transport of ricin: crosstalk between hVps34 and sorting nexins. Traffic 8:297-309

Slominska-Wojewodzka M, Gregers TF, Wälchli S, Sandvig K (2006) EDEM is involved in retrotranslocation of ricin from the endoplasmic reticulum to the cytosol. Mol Biol Cell 17:1664-1675

Smith DC, Lord JM, Roberts LM, Tartour E, Johannes L (2002) $1^{\text {st }}$ class ticket to class I: Protein toxins as pathfinders for antigen presentation. Traffic 3:697-704

Smith DC, Spooner RA, Watson PD, Murray JL, Hodge TW, Amessou M, Johannes L, Lord JM, Roberts LM (2006) Internalized pseudomonas exotoxin A can exploit multiple pathways to reach the endoplasmic reticulum. Traffic 7:379-393

Snyder MD, Rogers OC (1985) Intracellular movement of cell surface receptors after endocytosis: resialylation of asialo-transferrin receptor in human erythroleukemia cells. J Cell Biol 100:826-834

Stanley KK, Howell KE (1993) TGN38/41: a molecule on the move. Trends Cell Biol 3:252-255

Starr T, Forsten-Williams K, Storrie B (2007) Both post-Golgi and intra-Golgi cycling affect the distribution of the Golgi phosphoprotein GPP130. Traffic 8:1265-1279

Stenmark H, Olkkonen VM (2001) The Rab GTPase family. Genome Biol 2:REVIEWS3007.1-3007.7

Stieber A, Gonatas JO, Gonatas NK (1984) Differences between the endocytosis of horse radish peroxidase and its conjugate with wheat germ agglutinin by cultured fibroblasts. J Cell Physiol 119:71-76

Storrie B (2005) Maintenance of Golgi apparatus structure in the face of continuous protein recycling to the endoplasmic reticulum: making ends meet. Int Rev Cytol 244:69-94

Storrie B, White J, Rottger S, Stelzer EH, Suganuma T, Nilsson T (1998) Recycling of Golgi-resident glycosyltransferases through the ER reveals a novel pathway and provides explanation for nocodazole-induced Golgi scattering. J Cell Biol 143:1505-1521

Tai GH, Lu L, Wang TL, Tang BL, Goud B, Johannes L, Hong WJ (2004) Participation of the syntaxin 5/Ykt6/GS28/GS15 SNARE complex in transport from the early/recycling endosome to the trans-Golgi network. Mol Biol Cell 15:4011-4022

Tarrago-Trani MT, Storrie B (2007) Alternate routes for drug delivery to the cell interior: Pathways to the Golgi apparatus and endoplasmic reticulum. Adv Drug Deliv Rev 59:782-797

Torgersen ML, Skretting G, van Deurs B, Sandvig K (2001) Internalization of cholera toxin by different endocytic mechanisms. J Cell Sci 114:3737-3747

Torgersen ML, Wälchli S, Grimmer S, Skanland SS, Sandvig K (2007) Protein kinase $\mathrm{C} \delta$ is activated by Shiga toxin and regulates its transport. J Biol Chem 282:16317-16328

Trucco A, Polishchuk RS, Martella O, Di Pentima A, Fusella A, Di Giandomenico D, San Pietro E, Beznoussenko GV, Polishchuk EV, Baldassare M et al (2004) Secretory traffic triggers the formation of tubular continuities across Golgi subcompartments. Nat Cell Biol 6:1071-1081

Ullrich OS, Reinsch S, Urbe S, Zerial M, Parton RG (1996) Rab11 regulates recycling through the pericentriolar recycling endosome. $\mathrm{J}$ Cell Biol 135:913-924

Utskarpen A, Slagsvold HH, Iversen TG, Wälchli S, Sandvig K (2006) Transport of ricin from endosomes to the Golgi apparatus is regulated by Rab6A and Rab6A'. Traffic 7:663-672

Utskarpen A, Slagsvold HH, Dyve AB, Skanland SS, Sandvig K (2007) SNX1 and SNX2 mediate retrograde transport of Shiga toxin. Biochem Biophys Res Commun 358:566-570 
Van Deurs B, Tonnensen TI, Petersen OW, Sandvig K, Olsnes S (1986) Routing of internalized ricin and ricin conjugates in the Golgi complex. J Cell Biol 102:37-47

Van Deurs B, Petersen OW, Olsnes S, Sandvig K (1987) Delivery of internalized ricin from endosomes to cisternal Golgi elements is a discontinuous, temperature-sensitive process. Exp Cell Res 171:137-152

Varlamov O, Fricker LD (1998) Intracellular trafficking of metallocarboxypeptidase D in AtT-20 cells: localization to the trans-Golgi network and recycling from the cell surface. J Cell Sci 111:877-885

Vetterlein M, Ellinger A, Neumüller J, Pavelka M (2002) Golgi apparatus and TGN during endocytosis. Histochem Cell Biol 117:143-150

Vetterlein M, Niapir M, Ellinger A, Neumüller J, Pavelka M (2003) Brefeldin A-regulated retrograde transport into the endoplasmic reticulum of internalised wheat germ agglutinin. Histochem Cell Biol 120:121-128

Volz B, Orberger G, Porwoll S, Hauri H-P, Tauber R (1995) Selective reentry of recycling cell surface glycoproteins to the biosynthetic pathway in human hepatocarcinoma HepG2 cells. J Cell Biol 130:537-551

Von Zastrow M, Sorkin A (2007) Signaling on the endocytic pathway. Curr Opin Cell Biol 19:436-445

Wälchli S, Skanland SS, Gregers TF, Lauvrak SU, Torgersen ML, Ying M, Kuroda S, Maturana A, Sandvig K (2008) The MAP ki- nase p38 links Shiga toxin dependent signaling and trafficking. Mol Biol Cell (in press)

Wanschers BFJ, van de Vorstenbosch R, Schlager MA, Splinter D, Akhmanova A, Hoogenraad CC, Wieringa B, Fransen JAM (2007) A role for the Rab6B Bicaudal-D1 interaction in retrograde transport in neuronal cells. Exp Cell Res 313:3408-3420

Weissenböck A, Bogner E, Wirth M, Gabor F (2004) Binding and uptake of wheat germ agglutinin-grafted PLGA-nanospheres by Caco-2 monolayers. Pharma Res 21:1917-1923

White J, Johannes 1, Mallard F, Girod A, Grill S, Reinsch S, Keller P, Tzschaschel B, Echard A, Goud B, Stelzer HK (1999) Rab6 coordinates a novel Golgi to ER retrograde transport pathway in live cells. J Cell Biol 147:743-760

Yamane J, Kubo A, Nakayama K, Yuba-Kubo A, Katsuno T, Tsukita Sh, Tsukita Sa (2007) Functional involvement of TMF/ARA160 in Rab6-dependent retrograde membrane traffic. Exp Cell Res 313:3472-3485

Yoshino A, Setty SR, Poynton C, Whiteman EL, Saint-Pol A, Burd CG, Johannes L, Holzbaur EL, Koval M, McCaffery JM, Marks MS (2005) tGolgin-1(p230,golgin-245) modulates Shiga-toxin transport to the Golgi and Golgi motility towards the microtubuleorganizing centre. J Cell Sci 118:2279-2293

Zerial M, McBride H (2001) Rab proteins as membrane organizers. Nat Rev Mol Cell Biol 2:107-117 